\title{
POLÍTICA URBANA NO BRASIL: A DIFÍCIL REGULAÇÃO DE UMA URBANIZAÇÃO PERIFÉRICA
}

\author{
URBAN POLICY IN BRAZIL: THE DIFFICULT REGULATION OF A PERIPHERAL URBANIZATION
}

\section{RESUMO}

Neste artigo explora-se a difícil regulação do processo de urbanização brasileiro ao longo do século XX e os desafios que emergem no século XXI. Inicia-se com uma descrição do processo de urbanização no Brasil, visando associar a transformação de uma sociedade rural em outra de base urbano-industrial. Em seguida, destacase o avanço na legislação urbanística introduzida no período pós-constitucional, marcado por um aumento dos direitos sociais no país. E, apesar deste avanço, persistiu a urbanização periférica, característica do processo de urbanização brasileiro, o que permite situar o fracasso do avanço normativo das políticas urbanas em ter efetividade em prol de uma urbanização social e inclusiva da população pobre.

Palavras-chave: Processo de urbanização. Regulação urbanística. Urbanização periférica.

\section{ABSTRACT}

This article deals with the difficult regulation of the Brazilian urbanization process throughout the twentieth century and the challenges that emerge in the 21st century. It begins with a description of the urbanization process in Brazil, aiming to associate the transformation of a rural society into an urban-industrial base. Then we pointed out the advance in urban legislation introduced in the postconstitutional period, marked by an increase in social rights in the country. And despite this advance, the peripheral urbanization, characteristic of the Brazilian urbanization process, persisted, which allows us to recognize the failure of the normative advance of urban policies to be effective in favor of a social and inclusive urbanization of the poor population.

Keywords: Urbanization process. Urban regulation. Peripheral urbanization.
D Angela Moulin S. Penalva Santos ${ }^{\text {a }}$

a Universidade do estado do Rio de Janeiro (UERJ), Rio de Janeiro, RJ, Brasil

DOI: $10.12957 /$ geouerj.2020.47268

Correpondência: angelapenalva@terra.com.br

Recebido em: 8 set. 2019

Revisado em: 19 out. 2019 Aceito em: 12 dez. 2019 


\section{INTRODUÇÃO}

Foi somente em 1938, por meio do Decreto-Lei 31, que o governo federal estabeleceu a distinção entre território urbano e rural, oportunidade em que tratando os municípios então estabelecidos, passou a considerar o território urbano como aquele que se constituía pela população residente em sedes municipais ou de distritos, independentemente de sua função na rede urbana ou do tamanho de sua população.

Esse início do tratamento normativo do território urbano coincide com o processo de industrialização brasileiro, num contexto de crise da economia primário-exportadora. A emergência de uma sociedade de base urbano-industrial alterou a natureza da relação entre o rural e o urbano. Antes desse período, as cidades eram face urbana da agroexportação, mas a industrialização tornaria a cidade no lócus do capitalismo, o que levou a um intenso processo de migração rural-urbana.

A acelerada urbanização no país não foi acompanhada de políticas públicas adequadas para regular o crescimento das cidades, que experimentaram um processo de expansão urbana periférica. Em consequência, a dinâmica econômica prevaleceu sobre o ordenamento urbano e levou à formação de áreas metropolitanas nas quais problemas socioambientais emergiram, demandando respostas do poder público.

Neste artigo explora-se a difícil regulação do processo de urbanização brasileiro ao longo do século XX e os desafios que emergem no século XXI. Além da introdução, o artigo está constituído de mais três seções. Na primeira, sintetiza-se o processo de urbanização no Brasil, visando associar a transformação de uma sociedade rural em outra de base urbano-industrial; na segunda, o objetivo é destacar o avanço na legislação urbanística introduzida no período pós-constitucional, marcado por um aumento dos direitos sociais no país; na terceira analisa-se a persistência da urbanização periférica, característica do processo de urbanização brasileiro, o que permite situar o fracasso do avanço normativo das políticas urbanas em ter efetividade em prol de uma urbanização social e inclusiva da população pobre.

\section{O processo de urbanização no Brasil}

No último século, a população brasileira cresceu de 17 milhões para 170 milhões de habitantes. No início do século XX, apenas $17 \%$ dessa população vivia em cidades, situação que se inverteu no fim do século, quando esse percentual já era de $81 \%$, elevando-se ainda mais no último censo demográfico, realizado em 2010, que apurou uma taxa de urbanização de $84 \%$. Tamanha mudança demográfica está associada à passagem da dinâmica econômica de base primária e exportadora para uma de base urbano-industrial.

O processo brasileiro de industrialização intensificou-se após 1930, quando a crise da agroexportação desestruturou a atividade rural e liberou a força de trabalho, a qual, assim, passou a buscar na cidade novas oportunidades de emprego. A partir de então, formaram-se áreas metropolitanas nucleadas pelas capitais 
estaduais, tendo São Paulo e Rio de Janeiro como as mais importantes, nas quais apenas as capitais estaduais respondem por 11\% e 5\%, respectivamente, do PIB brasileiro em 2015 (IBGE, 2017).

Entre 1930 e 1980, a economia brasileira cresceu dinamizada pela Indústria, o que se fez acompanhar pelas migrações rural-urbanas. Houve forte diminuição do peso demográfico da população rural, com a concentração da população na região Sudeste, o epicentro da economia industrial. Mas, dentro de cada macrorregião, também se manifestou o processo de concentração em torno das capitais estaduais. Portanto, a população brasileira experimentou uma intensificação de sua taxa de urbanização, com concentração nas maiores cidades. A tabela a seguir apresenta a evolução demográfica no país, no período 1970-2010.

Tabela 1. Evolução da população e taxa de urbanização no Brasil, 1970-2010. Fonte: Censos Demográficos, IBGE.

\begin{tabular}{cccc}
\hline ANOS & POPULAÇÃO TOTAL (A) & POPULAÇÃO URBANA (B) & (B)/(A)\% \\
\hline 1970 & 93.134 .846 & 52.097 .269 & 55,94 \\
1980 & 119.011 .052 & 80.437 .327 & 67,59 \\
1990 & 146.825 .475 & 110.990 .990 & 75,59 \\
2000 & 169.799 .170 & 137.953 .959 & 81,25 \\
2010 & 190.755 .799 & 160.925 .804 & 84,36 \\
\hline
\end{tabular}

Desde a década de 1980, a Indústria vem perdendo peso na formação do PIB, ainda que a polarização espacial se tenha mantido. As grandes cidades se tornaram economias de serviços num contexto em que as novas tecnologias de informação, conjugadas a uma nova divisão social do trabalho, sustentaram a atração locacional dos grandes centros.

Os defensores das grandes cidades as veem como locais que favorecem a diversidade (Jacobs, 2003), que comandam espaços de fluxos (Castells, 1999) e que estimulam a inovação, através da disseminação do conhecimento tácito que é produzido por seus residentes e, principalmente, por seus laboratórios de pesquisa (Storper; Venables, 2005; Glaeser, 2011). O principal atributo dessas cidades seria sua capacidade de reunir a população com elevados níveis de escolaridade, interagindo e produzindo novidades. A força econômica desses grandes aglomerados seria o burburinho, como apontado por Storper e Veneables (2005), que favorece a diversidade, além dos ganhos de escala associados a economias de escopo.

Tamanha força econômica, por sua vez, traduz-se em elevada participação dessas cidades na distribuição espacial das oportunidades de trabalho, que estariam relacionadas à dinâmica atual do capitalismo contemporâneos. Segundo a teoria urbana, o processo de globalização tem contribuído para modificar o modo como se estrutura o território desde que as finanças sucederam a indústria como atividade dominante (Castells, 1999; Sasken, 2003; Hall, 2004; Harvey, 2011). O resultado tem sido o fortalecimento - e 
não o enfraquecimento - das metrópoles, que se tornaram pontos essenciais na economia contemporânea, tendo em vista a concentração de serviços especializados e de grande porte, os quais permitiriam a conexão com outras metrópoles num mundo cada mais interdependente. Trata-se daquilo que Milton Santos (1996) denominou "meio técnico" adequado à acumulação capitalista disponível nas grandes áreas urbanas.

Essa marcada polarização espacial vem sendo experimentada no Brasil. Segundo o Censo Demográfico de 2010, a população brasileira atingiu 191 milhões de habitantes, dos quais 54,75\% residiam em apenas 283 dentre os 5.570 municípios brasileiros. Esses 283 são os municípios com mais de 100 mil habitantes, dos quais 27 são capitais estaduais e os demais estão em seu entorno (cidades metropolitanas) ou em áreas fora das regiões metropolitanas (cidades não-metropolitanas).

Tabela 2. Participação das maiores cidades na população e PIB brasileiros (2000 e 2010). Fonte: Autora. Base de dados: IBGE - Censos Demográficos de 2000 e 2010 e Contas Nacionais.

\begin{tabular}{ccccc}
\hline CIDADES & POPULAÇÃO (2000) & $\begin{array}{c}\text { PIB } \\
\mathbf{( 2 0 0 0 )}\end{array}$ & POPULAÇÃO (2010) & $\begin{array}{c}\text { PIB } \\
\mathbf{( 2 0 1 0 )}\end{array}$ \\
\hline $\begin{array}{c}\text { Capitais estaduais } \\
\text { Cidades }\end{array}$ & 22,54 & 37,06 & 23,83 & 34,03 \\
$\begin{array}{c}\text { metropolitanas } \\
\text { Cidades não }\end{array}$ & 15,61 & 18,94 & 15,95 & 19,13 \\
metropolitanas & 14,47 & 16,33 & 14,91 & 17,13 \\
Média & & & & \\
Brasil & 52,61 & 72,33 & 54,69 & 70,30 \\
& $100 \%$ & $100 \%$ & $100 \%$ & $100 \%$ \\
\hline
\end{tabular}

Na primeira década do século XXI, o já elevado peso desse grupo de apenas $5 \%$ do número de municípios brasileiros experimentou crescimento em seu peso demográfico, mas não no PIB. No entanto, a perda de participação percentual de 72,33\% para 70,30\% é muito incipiente em comparação à grandeza dessa participação. Esse resultado explica por que esses municípios seguem oferecendo 3 a cada 4 empregos (saldo líquido entre admissões e demissões) na referida década (CAGED, 2000 e 2010).

A segunda década do século XXI tem sido marcada por forte crise econômica que se manifestou em queda no PIB brasileiro a partir de 2014, destacando-se o biênio 2015/2016 quando a perda alcançou -3,8\% e $-3,6 \%$, respectivamente. Tamanho declínio afeta mais fortemente a economia dessas grandes cidades, dada a queda na arrecadação tributária, enquanto as cidades de menor porte foram socorridas em seus orçamentos pelo aumento de transferências intergovernamentais (Santos, 2018).

A crise só não foi mais forte devido ao dinamismo do agronegócio, sustentando exportações. Em tal contexto, é possível que tenha diminuído o peso demográfico e econômico dessas grandes cidades e tenha havido alguma redistribuição espacial da população. Entretanto, dificilmente terá alimentado o crescimento das pequenas cidades. Muito provavelmente terá se refletido no aumento do peso de cidades de médio porte, 
particularmente daquelas situadas em áreas produtoras de commodities primárias. Tal hipótese, entretanto, só poderá ser avaliada após a realização do censo demográfico de 2020, previsto para setembro daquele ano.

As políticas públicas urbanas representam a forma pela qual o Estado se estrutura para ordenar o espaço urbano. Desde a década de 1930, a migração rural-urbana desafia o poder público no sentido de aumentar a provisão de acesso aos meios de consumo coletivo, como a infraestrutura urbana e social. Essa provisão dependeu da competição por alocação de verbas no orçamento com os demais gastos públicos, ganhando maior prioridade apenas quando os efeitos negativos da falta de desenvolvimento urbano se tornaram graves, o que, inclusive, suscitou diversos movimentos sociais voltados à temática urbana, a partir da década de 1960 , momento em que a população urbana ultrapassou a rural.

\section{Como é a regulação normativa da urbanização brasileira?}

Se a polarização espacial está disseminada pela maioria dos países, a forma como cada poder público enfrenta essa questão varia muito. No caso brasileiro, as políticas públicas urbanas experimentaram uma fase inicial em que prevaleceu uma "não-política", ou seja, o Estado negligenciou os problemas associados à urbanização. Essa realidade seria modificada após 1964, quando um regime autoritário foi instituído e muitas reformas institucionais foram realizadas, incluindo a introdução de políticas urbanas e o reconhecimento legal de nove regiões metropolitanas. Essa etapa se esgota com o retorno da ordem democrática, em 1985, seguida da entrada em vigor de uma nova Constituição, em 1988, que pode ser considerada um ponto de inflexão na regulação urbanística do país.

Política urbana no Brasil antes da Constituição de 1988

A partir de 1930, a intensificação da urbanização, com a consolidação das primeiras metrópoles brasileiras, levou a iniciativas do poder público para enfrentar os problemas urbanos. Algumas importantes reformas foram introduzidas no cenário político e econômico, mas não houve um tratamento institucionalizado da questão urbana, o que foi considerado uma não política (Cintra, 1978). Ainda assim, cabe mencionar a legislação que dificultava a retomada de imóveis para aluguel, justificada como medida para enfrentar o aumento dos valores locatícios, em um contexto de crescente disputa pela terra urbana. Como resultado, houve diminuição do investimento voltado à construção imobiliária, e isso repercutiu na falta de moradia, o que levou a soluções informais de autoconstrução - às quais, em muitos casos, ocuparam áreas públicas e consideradas não edificáveis pela legislação vigente. 
O resultado dessa "não política", ou omissão do poder público diante dos desafios da urbanização crescente, foi a produção da "cidade ilegal", aquela que não era reconhecida como parte das cidades, ainda que fosse uma realidade fática. O não reconhecimento dessa produção informal impedia a execução de políticas públicas que incorporassem essas áreas na política de urbanização da cidade formal.

A informalidade na produção da cidade inclui a formação de favelas, ou seja, aglomerados urbanos irregulares tanto em termos fundiários como em termos urbanísticos, mas também loteamentos irregulares. Estes últimos, em geral, são irregulares em termos urbanísticos, ainda que muitos se refiram a imóveis que têm a propriedade fundiária reconhecida.

As favelas surgiram no início do século XX, na então capital do país, a cidade do Rio de Janeiro. A abolição da escravatura e algumas obras públicas de forte impacto urbanístico levaram os pobres a buscarem moradias na encosta de morros, com a intenção de se manterem próximos aos polos de emprego, concentrados no centro da cidade. Essa alternativa de moradia foi a possibilidade encontrada num contexto em que o poder público não investia em políticas habitacionais e/ou de mobilidade urbana. Assim, em 1950, 7\% da população do Rio de Janeiro vivia em favelas, percentual que seguiu se elevando, vindo a atingir $22 \%$ dos habitantes no fim do século XX. De acordo com os últimos dados censitários, em 2010, aproximadamente 11,4 milhões de pessoas ( $6 \%$ da população) viviam em aglomerados subnormais, termo técnico que o IBGE utiliza para denominar as favelas. Em todo o país foram identificadas 6.329 favelas localizadas em 323 dentre os 5.565 municípios brasileiros então instalados. A favelização é, portanto, um problema presente num grupo pequeno de cidades, naquelas de médio e grande porte demográfico.

Conforme os resultados censitários de 2010, as capitais estaduais com maior proporção de habitantes que moram em favelas são Belém, que tem mais da metade da população $(53,9 \%)$ vivendo nesse tipo de aglomeração, seguida por Salvador (26,1\%), São Luís (24,5\%) e Recife (23,2\%). As duas maiores cidades do país, São Paulo e Rio de Janeiro, têm 11\% e 22\% da população morando em favelas, respectivamente. Apesar desse percentual menor, é nessas duas cidades que se encontra o maior número absoluto de pessoas faveladas: 2.162.368 em São Paulo e 1.702.073 no Rio de Janeiro.

Os loteamentos resultam da mudança do uso da terra rural nas franjas urbanas para uso residencial. À medida em que as migrações rural-urbanas foram se acentuando, alinhadas com o processo de industrialização e com a manutenção de uma estrutura fundiária muito concentrada, ocorreu a expansão urbana por loteamentos irregulares. Assim, houve crescimento extensivo das cidades com a expansão mais acentuada na periferia das cidades. O poder público, então, tentou ordenar os loteamentos urbanos por meio da edição de uma lei federal (Lei 6.766/79). Trata-se, contudo, de uma legislação muito restritiva, que prevê inúmeras obrigações aos loteadores, onerando significativamente o empreendimento imobiliário, o que inviabiliza financeiramente aqueles voltados à moradia popular (Botelho, 2007; Costa, 2001). 
Apesar disso, no entanto, o reconhecimento legal da promessa de compra e venda dos lotes estimulou a disseminação dos loteamentos irregulares destinados à população de baixa renda, na expectativa de que os adquirentes constituíssem força política suficiente para levar o poder público a urbanizar a área loteada, responsabilidade que deveria ser atendida pelos loteadores. Como resultado, houve a realimentação - e não a mitigação- da desordem urbana, o que agravou a crise nas cidades. Em 2001, uma pesquisa do IBGE sobre o perfil da gestão municipal no Brasil identificou a presença de loteamentos irregulares em $48 \%$ dos municípios. Esse resultado sugere que os loteamentos irregulares proliferaram não apenas nas cidades de médio e grande portes, mas também nos municípios pequenos.

O desafio da forte urbanização da população foi um problema que mereceu enfrentamento pelas políticas públicas após a ruptura institucional ocorrida em 1964. Na década de 1960 foram criados o Serviço Federal de Habitação e Urbanismo (SERFHAU) e o órgão financeiro que cuidaria de executar as políticas, o Bando Nacional de Habitação (BNH), responsável não só pelo financiamento da construção habitacional, mas também pela gestão da política de saneamento, instituída pelo Plano Nacional de Saneamento (PLANASA).

A importância do BNH pode ser inferida pelo balanço de sua contribuição ao mercado imobiliário brasileiro: até a sua extinção, em 1986, o banco foi responsável pelo financiamento de $24 \%$ das unidades habitacionais construídas no país. Responsabilizou-se, ademais, pela expansão da cobertura de esgotamento sanitário, transferindo para as companhias estaduais de água e saneamento os recursos com os quais elas financiaram as obras.

Nas décadas de 1960 e 1970, o governo militar usou a malha urbana para articular o território brasileiro, investindo na implantação de um conjunto de redes: viária, de energia e de comunicação (Becker; Egler, 1993). Ademais, reconheceu as metrópoles como territórios que mereciam um tratamento específico, diferente da política municipal, o que levou à institucionalização de 9 regiões metropolitanas, responsáveis pela articulação dos serviços públicos no território.

Trata-se de um período (1964-1985) que testemunhou importantes avanços na política urbana, embora ainda muito associados à reorganização do espaço em função das necessidades da industrialização (MonteMór, 2005). Assim, por exemplo, as cidades passariam a receber muitas obras viárias, consideradas necessárias para adaptá-las ao uso do automóvel, cuja indústria foi um dos sustentáculos do processo industrial no país. O financiamento dessas obras era assegurado pela criação de um fundo com recursos vinculados a obras viárias, o Fundo Rodoviário Nacional.

Tal como ocorre em todas as reformas urbanas, alguns problemas foram enfrentados, mas logo emergiram outros, como, por exemplo, os derivados da insustentabilidade ambiental da urbanização extensiva. Questões ainda pendentes de tratamento adequado, caso do saneamento, somaram-se às questões 
de mobilidade urbana e segurança pública. Em consequência, a deterioração das condições de vida, especialmente daquela população residente na cidade informal, demandou crescente financiamento para o investimento em serviços públicos. Nesse contexto, reemergiram os movimentos sociais, dentre os quais se destaca o Movimento Nacional pela Reforma Urbana, muito ativo nas décadas de 1970 e 1980, tendo sido responsável pela introdução de um capítulo sobre política urbana na Constituição da República de 1988.

Os avanços normativos pós-Constituição de 1988

A Constituição de 1988 inaugurou uma nova abordagem para a questão urbana. A partir de então, esta deixou de ser entendida como modernização do espaço urbano dentro do processo de industrialização e passou a se identificar com o direito à cidade. Além de elevar o município à condição de ente federativo, a Constituição incluiu dois importantes artigos alinhando a política urbana como responsabilidade municipal (art. 182) e simplificando a regularização fundiária urbana ao definir em 5 anos o tempo de posse mansa da terra, ou seja, a posse não conflituosa, para fins de usucapião (art. 183).

A regularização fundiária foi um dos mais relevantes instrumentos para o ordenamento das cidades. Dado o crescimento da população que reside em favelas e em loteamentos irregulares, foi preciso contornar a informalidade desse tipo de ocupação com a criação das chamadas "zonas (ou áreas) especiais de interesse social". Ao definir o contorno territorial dessas zonas, a legislação municipal tornou possível a identificação de localidades em que as exigências da legislação urbanística seriam especiais, o que permitiria regularizar urbanisticamente comunidades inteiras. Essa estratégia foi um passo importante para que deixasse de ser regra a política de remoção de tais comunidades. Ao contrário, elas passaram a receber investimentos públicos, com projetos de urbanização de favelas, a exemplo do Projeto Favela Bairro, no município do Rio de Janeiro, durante a década de 1990.

No artigo 182, declara-se o município como responsável pela política urbana, sendo que aqueles com população superior a 20 mil habitantes são obrigados a elaborar o seu Plano Diretor, considerado instrumento básico para a política de desenvolvimento e expansão urbana. A propriedade urbana deixa de ser considerada absoluta, já que precisa cumprir sua função social, entendida como aquela que atende às exigências de ordenação da cidade no Plano Diretor. Ademais, permite que o poder público municipal, mediante lei específica para área incluída no Plano Diretor, exija do proprietário do solo urbano não edificado, subutilizado ou não utilizado, seu aproveitamento adequado.

Ainda que o município seja o ente federativo responsável pela política urbana, o governo federal editou uma série de leis que regulamentaram avanços normativos instituídos pela Constituição. Uma síntese de cada uma destas leis é apresentada a seguir. 
i) Lei do Estatuto da Cidade

A maior parte dos novos instrumentos jurídicos criados para regular o adequado aproveitamento da terra urbana só passaria a ter efetividade após a lei federal que regulamentou os dois artigos constitucionais, a Lei 10.257/2001, denominada Estatuto da Cidade. O novo tratamento do direito de propriedade gerou muita resistência política, motivo pelo qual a referida lei somente seria aprovada 13 anos depois da promulgação da Constituição.

A lei define que a política urbana tem por objetivo ordenar o pleno desenvolvimento das funções sociais da cidade e da propriedade urbana mediante algumas diretrizes, com destaque para: i) garantia do direito a cidades sustentáveis, entendido como o direito à terra urbana, à moradia, ao saneamento ambiental, à infraestrutura urbana, ao transporte e aos serviços públicos, ao trabalho e ao lazer, para as gerações presentes e futuras; ii) gestão democrática da cidade; iii) cooperação entre os governos, a iniciativa privada e os demais setores da sociedade no processo de urbanização, em atendimento ao interesse social.

No que tange à diretriz relacionada à ordenação e ao controle do uso do solo, a lei estabelece muitos objetivos. É preciso evitar, principalmente: a utilização inadequada dos imóveis urbanos; o parcelamento do solo, a edificação ou o uso excessivo ou inadequado em relação à infraestrutura urbana; e a retenção especulativa de imóvel urbano que resulte em subutilização ou não utilização. Outras diretrizes que merecem destaque referem-se a: justa distribuição dos benefícios e ônus decorrentes do processo de urbanização; adequação dos instrumentos de política econômica, tributária e financeira e dos gastos públicos aos objetivos do desenvolvimento urbano, de modo a privilegiar os investimentos geradores de bem-estar geral e a fruição dos bens pelos diferentes segmentos sociais; a regularização fundiária e urbanização das áreas ocupadas por população de baixa renda; mediante o estabelecimento de normas especiais de urbanização, uso e ocupação do solo e edificação, levando-se em consideração a situação socioeconômica da população e as normas ambientais.

Para alcançar estes objetivos, foram introduzidos instrumentos gerais de política urbana, como a obrigatoriedade do plano diretor e sua articulação com os instrumentos de planejamento para a administração pública - por exemplo, os planos plurianuais e investimento a cada 4 anos, a lei anual de diretrizes orçamentárias e a lei orçamentária anual. Mas foram os novos instrumentos jurídicos que causaram maior impacto na gestão do território urbano. Tais instrumentos incluem: i) parcelamento, edificação ou utilização compulsórios; ii) concessão de uso especial para fins de moradia; iii) direito de superfície; iv) outorga onerosa do direito de construir; v) operações urbanas consorciadas; e vi) transferência do direito de construir, entre os mais importantes. Cada um desses novos instrumentos deve ter uma lei municipal que regule sua utilização no território do município, o que esvazia de conteúdo o instrumento que, embora incluído no Estatuto da Cidade, não conte com regulamentação municipal. 
Cabe destacar que o Plano Diretor somente é obrigatório no caso dos municípios que contem com mais de 20 mil habitantes ou que façam parte de regiões metropolitanas, além dos demais casos estabelecidos no art. 41 do Estatuto da Cidade. Isso significa dizer que a maior parte dos municípios brasileiros está desobrigada de elaborar o principal instrumento de ordenamento urbanístico, como se infere da tabela a seguir, que apresenta a distribuição dos municípios segundo classes de tamanho de sua população.

Tabela 3. Distribuição dos municípios brasileiros segundo as classes de tamanho da população e o respectivo peso na população brasileira, 2010. Fonte: Censo Demográfico 2010, IBGE.

\begin{tabular}{ccc}
\hline $\begin{array}{c}\text { MUNICÍPIOS/ANOS (1.000 } \\
\text { HABITANTES) }\end{array}$ & NÚMERO DE MUNICÍPIOS (2010) & $\begin{array}{c}\text { PESO PERCENTUAL NA } \\
\text { POPULAÇÃO BRASILEIRA (\%) }\end{array}$ \\
\hline$<20$ & 3.914 & 17,1 \\
Entre 20 e 50 & 1.043 & 16,4 \\
Entre 50 e 100 & 325 & 11,7 \\
Entre 100 e 250 & 184 & 14,5 \\
Entre 250 e 500 & 61 & 11,0 \\
Entre 500 e 2.000 & 32 & 14,8 \\
$>$ >2. Mil & 6 & 14,5 \\
Total & 5.565 & 100,0 \\
\hline
\end{tabular}

Ainda que o município seja o responsável pela política urbana mediante a elaboração de seu plano diretor, o Estatuto da Cidade atribui algumas responsabilidades à União. O governo federal deve editar normas gerais, em especial as relativas à cooperação interfederativa e às diretrizes de desenvolvimento urbano, incluindo habitação, saneamento e transporte urbano.

Tais normas gerais foram editadas após uma importante inovação na estrutura do poder público no que concerne à política urbana: em 2003, foi criado o Ministério das Cidades, responsável pela tentativa de coordenar as políticas setoriais com impacto no processo de desenvolvimento urbano.

Cabe destacar que as três esferas de governo devem elaborar planos de ordenação do território em escala nacional (União), regional (estados) e local (municípios). As competências federal e municipal estão bem delimitadas, enquanto, no caso dos estados, a competência é residual. Ainda assim, os estados ficaram responsáveis pelas normas relativas às regiões metropolitanas já existentes desde 1973, instituídas pela Lei Complementar n. 14. O resultado foi a transformação da política urbana em uma arena da política dominada pelo governo federal e os municipais.

ii) Lei dos Consórcios Públicos

A Lei 11.107/2005 regulamentou a contratação de consórcios públicos, os quais passaram a ter personalidade jurídica, sendo objeto de contrato, o que torna mais difícil que uma das partes o abandone. Já existiam consórcios, especialmente aqueles que reuniam alguns municípios para a execução de políticas que 
requerem uma escala superior à da maioria dos municípios brasileiros, de pequeno porte demográfico, caso do saneamento básico.

Desde a sua regulamentação, em 2007, os consórcios intermunicipais têm sido mais frequentes nas políticas de saneamento e saúde. Têm sido mais frequentes também entre os municípios pequenos e, em especial, entre aqueles de porte demográfico semelhante. Nos demais casos que envolvem um município maior que seus vizinhos, observa-se resistência na formação de consórcios em função do desequilíbrio de poder exercido pelo município principal. Justamente nesses casos é que se mostra necessária a coordenação dos governos estaduais, ainda muito incipientes.

iii) Lei do Sistema Nacional de Habitação e Interesse Social

Ainda no ano de 2005, entrou em vigor a Lei 11.124 que instituiu o Sistema Nacional de Habitação de Interesse Social (SNHIS). Essa lei federal inaugurou uma nova política habitacional ao reconhecer que apenas regular o mercado imobiliário não seria suficiente para ampliar a cobertura da população com acesso ao direito social à moradia. Era necessário subsidiar parte da produção da moradia voltada à população de baixa renda.

Pesquisa realizada sobre o déficit habitacional brasileiro identificou que as famílias com renda inferior ao equivalente a 3 salários mínimos correspondem a 90\% do total (FJP, 2013). O déficit não é constituído apenas por novas moradias a serem construídas, mas também por aquelas consideradas inadequadas. $A$ inadequação pode ser aferida pela falta de acesso à infraestrutura (acesso à rede geral de abastecimento de água, à rede geral de esgoto e à coleta de lixo) ou pelo peso de seu custo na renda das famílias (gasto superior a $30 \%$ da renda familiar com aluguel, muitos moradores por quarto ou mais de uma família coabitado o mesmo domicílio). Assim, o déficit habitacional pode ser enfrentado mediante: i) construção de novas moradias; ii) expansão da rede de infraestrutura urbana para incluir todos os domicílios permanentes; e iii) controle do preço da terra urbana para não onerar demasiadamente as famílias de baixa renda (rendimento inferior a 3 salários mínimos).

Os municípios contam com instrumentos urbanísticos e jurídicos para induzir o uso social da propriedade urbana, mas não tem autonomia orçamentária para enfrentar um programa de construção de moradia social em larga escala. Por isso, o governo federal instituiu a Política Nacional de Habitação de Interesse Social, a ser financiada com recursos federais. Para executá-la, estados e municípios precisam aderir ao SNHIS, cumprindo três obrigações: i) criar um fundo específico para gerir as receitas; ii) instituir os conselhos gestores desse fundo; e iii) aprovar seus planos de habitação - Plano Estadual de Habitação de Interesse Social (PEHIS) e Plano Local de Habitação de Interesse Social (PLHIS). Trata-se de um modelo de 
adesão no âmbito da política federal alinhado com a responsabilidade compartilhada entre os três entes federativos.

Para executar a política local de habitação de interesse social foi criado o Programa Minha Casa Minha Vida (PMCMV) pela Lei 11.977/2009. Suas metas iniciais constituíam em: i) construir 1 milhão de moradias destinadas às famílias com renda de até 10 salários mínimos, além de antecipar outros instrumentos e ações previstos no Plano Nacional de Habitação, como a distribuição dos recursos de acordo com o déficit; ii) regionalizar o custo dos imóveis; iii) contar com a contrapartida dos entes federativos; iv) desempenhar papel significativo na regularização fundiária visando complementar o acesso à moradia.

A subvenção econômica é limitada à faixa de 6 salários mínimos, podendo ser acumulada com subsídios dos estados e dos municípios, sendo que as famílias com até 3 salários mínimos recebem subsídio integral. Os adquirentes cuja renda familiar situa-se entre 6 e 10 salários mínimos beneficiam-se com a redução dos custos do seguro e o acesso ao fundo garantidor (garantia de pagamento aos agentes financeiros da prestação mensal do financiamento). Os recursos são destinados exclusivamente à produção ou à aquisição de novas unidades habitacionais nas áreas urbanas ou à requalificação de imóveis já existentes nas áreas já consolidadas.

iv) Lei do Saneamento Ambiental e Resíduos Sólidos

A Lei 11.445/2007 estabelece as diretrizes nacionais para o saneamento básico e resíduos sólidos. A entrada em vigor dessa norma permitiu que o arcabouço normativo brasileiro passasse não só a contar com conceitos jurídicos importantes, como saneamento básico ou universalização do saneamento, mas também tratou de organizar a atuação dos entes federativos no que tange à implementação das políticas públicas em questão.

Embora seja possível identificar evidente preocupação social na implementação dos sistemas de saneamento e fornecimento de água, boa parte do mencionado instrumento normativo está concentrada em criar um marco regulatório claro para as respectivas questões operacionais da política pública, especialmente no que se refere à forma de concessão e definição de tarifas.

Como em outras políticas públicas, o Município recebeu obrigações de natureza executiva. Cabe lembrar, todavia, que parte expressiva dos recursos públicos virão da União, como no caso da Política Nacional de Habitação de Interesse Social.

Não obstante, somente em 2010, com a edição da Lei 12.305/10, que instituiu a Política Nacional de Resíduos Sólidos (PNRS), o Brasil passou a contar com um instrumento normativo de caráter nacional para tratar da referida política pública. Anteriormente, a regulação sobre o tema estava majoritariamente contida 
nas resoluções do Conselho Nacional de Meio Ambiente (CONAMA) e em menções esparsas previstas em outras normas, como na Lei $11.445 / 2007$.

Apesar do prolongado intervalo até a sua edição (o projeto tramitou por 21 anos no Congresso Nacional), diversos dispositivos normativos importantes foram introduzidos, dentre os quais cabe destacar a divisão de competências para atuação dos entes federativos, a instituição de sistemas de logística reversa e a definição de responsabilidade compartilhada pelo ciclo de vida dos produtos.

Tendo em vista a impossibilidade de dissociar a questão social atinente aos catadores de lixo da questão das políticas públicas de gestão dos resíduos sólidos, o legislador não só previu a extinção dos lixões (cujo prazo expirou em 2014), como também procurou oferecer alternativas jurídicas para esses atores sociais. Por exemplo, a facilitação, por meio da dispensa de licitação, na contratação de associações de cooperativas para integrar os sistemas de coleta seletiva.

Como resultado de um tratamento formalmente igualitário dispensado a todos os municípios brasileiros, a Associação Brasileira de Município afirma que parte significativa dos referidos entes, em particular a grande maioria deles com menos de 50 mil habitantes, não reúne condições técnicas nem financeiras para cumprir a legislação em vigor. Assim, ao ignorar essa realidade, o legislador federal submete o executivo municipal a condições extremamente precárias de autodeterminação, sujeitando-o a incorrer em crime de improbidade administrativa.

v) Lei da Política Nacional de Mobilidade Urbana

A Lei 12.587/2012 é um instrumento da política de desenvolvimento urbano que tem por objetivo integrar os diferentes modos de transportes e a melhora da acessibilidade e da mobilidade no território do município. Em seu artigo 2, declara que visa "contribuir para o acesso universal à cidade, o fomento e a concretização das condições que contribuem para a efetivação dos princípios, objetivos e diretrizes da política de desenvolvimento urbano". Representa, portanto, um complemento das responsabilidades da União quanto ao processo de desenvolvimento urbano, após legislar sobre a política de habitação de interesse social e sobre a política de saneamento ambiental, conforme previsto no Estatuto da Cidade.

O transporte público coletivo, no entanto, guarda algumas peculiaridades em relação à habitação. Como o saneamento, trata-se de uma função pública de interesse comum de municípios conurbados, como no caso daqueles situados em regiões metropolitanas ou quaisquer outros aglomerados urbanos. Depende, portanto, de cooperação interfederativa para ter efetividade. Esse é outro desafio da política urbana.

Os princípios, diretrizes e objetivos da política de mobilidade são aqueles estabelecidos pelo Estatuto da Cidade, o que torna imperativo que essa política esteja alinhada com o plano diretor municipal, envolvendo 
a participação social para uma gestão democrática e ambientalmente sustentável da cidade, além da justa distribuição dos benefícios e ônus decorrentes do uso dos diferentes modais e serviços.

É curioso e, ao mesmo tempo, alvissareiro que inclua entre suas diretrizes, o incentivo ao desenvolvimento científico-tecnológico e ao uso de energias renováveis e menos poluentes. O incentivo ao uso destas energias é inédito e só aparece nas normas urbanísticas a partir da Lei 12.836/2013, que altera o Estatuto da Cidade e modifica três de seus artigos com o objetivo de reforçar a preocupação com o meio ambiente nas políticas urbana. A lei prevê que a União preste os serviços de transporte público interestadual de caráter urbano, estimulando também ações coordenadas e integradas entre municípios e estados nas áreas conurbadas, aglomerações urbanas e regiões metropolitanas, além de cidades gêmeas (aquelas que se situam em países fronteiriços).

No que tange aos estados, há previsão de que possam delegar aos municípios a organização e a prestação do serviço intermunicipal de caráter urbano, desde que constituído um consórcio público ou um convênio de cooperação com esse fim. Como já mencionado, a constituição de um consórcio público confere maior estabilidade aos acordos intermunicipais, sendo muito pertinentes nestas políticas.

Assim como ocorre com as políticas de habitação de interesse social e saneamento ambiental, também no caso da mobilidade urbana está previsto um plano: o Plano de Mobilidade Urbana, considerado o instrumento de efetivação da política nacional de mobilidade urbana, devendo ser atualizado a cada 10 anos, assim como o Plano Diretor Municipal. Da mesma forma, a obrigatoriedade do plano também abrange os municípios com mais de 20 mil habitantes, e o prazo para se adequar ao plano diretor é de até 3 anos, findo o qual o município fica impossibilitado de receber recursos orçamentários federais destinados à mobilidade urbana. Esse prazo foi estendido para 7 anos, numa atualização da norma como ocorrera com outros planos, como o já mencionado anteriormente Plano Nacional de Saneamento e Resíduos Sólidos e do Estatuto da Metrópole, a seguir analisada.

vi) Lei do Estatuto da Metrópole

A edição da Lei 13.089/2015, conhecida como o Estatuto da Metrópole, foi festejada como um importante avanço normativo para induzir melhor governança de territórios que não são reconhecidos como entes federativos, como o caso das regiões metropolitanas e demais aglomerados urbanos. Nestes territórios, a responsabilidade pela gestão de funções públicas de interesse comum demanda melhor coordenação interfederativa, como já tinha sido reconhecida desde os anos 1970 quando foram instituídas as primeiras regiões metropolitanas pelo governo federal.

Com a redemocratização e entrada em vigor da Constituição de 1988, as regiões metropolitanas deixaram de ser criadas pela União, passando para a competência dos governos estaduais. Mas, ao mesmo 
tempo, os municípios deixaram de ser tutelados pelos Estados e foram alçados à condição de entes federativos.

Ao estabelecer critérios para a classificação das aglomerações urbanas e estimular a governança interfederativa nestes territórios, o Estatuto da Metrópole reconheceu os limites da atual estrutura políticoterritorial e forneceu alternativas para conciliar o federalismo de três entes vigentes no Brasil, considerado cláusula pétrea pela Constituição de 1988.

Em tais condições, a governança destes territórios passou a depender de maior cooperação voluntária entre os entes federativos. A maior fragmentação territorial advinda com a criação de aproximadamente 1.500 municípios desde a década de 1980 só faria elevar o desafio da governança territorial (Santos, 2008; 2017a).

Mas, como estimular a cooperação interfederativa entre entes considerados igualmente autônomos do ponto de vista jurídico, ainda que muitos desiguais em termos econômicos e demográficos?

O legislador desenvolveu critérios obrigatórios para a condução de uma possível "gestão plena" dessas novas unidades territoriais urbanas, quais sejam, a existência de estrutura de governança interfederativa própria; plano de desenvolvimento urbano integrado aprovado mediante lei estadual; e compartilhamento de responsabilidades entre entes da Federação em termos de organização, planejamento e execução de funções públicas de interesse comum.

Importante notar que, apesar dessa estrutura de governança interfederativa prever a participação da sociedade civil em caráter deliberativo nos processos de planejamento e execução de ações e políticas públicas, a composição desses representantes não foi prevista, dando margem para os legislativos estaduais desenvolverem diversos modelos de instâncias populares colegiadas.

Como forma de induzir o comportamento estadual e municipal à elaboração e constante revisão de tais documentos técnicos, a União reproduz estratégia reiteradamente adotada nos últimos governos (2003-2016) e passa a condicionar seu apoio para as iniciativas dos estados e dos municípios à existência dos planos no formato e conteúdo definidos pelo Estatuto da Metrópole. Ou seja, ainda que a União não realize uma intervenção direta no processo de gestão interfederativa, sua presença e capacidade de centralização se manifestam, principalmente, na medida em que a obtenção de recursos federais está condicionada a obediência estrita dos contornos definidos na legislação federal.

O reconhecimento de novas formas territoriais pelo Estatuto da Metrópole apresenta-se como importante avanço normativo na gestão destes espaços. Apesar disso, se a legislação busca induzir o comportamento cooperativo interfederativo, ficou por avançar em formas também cooperativas no financiamento dos serviços comuns. Ao vetar a Seção II, onde estava prevista a criação do Fundo Nacional de 
Desenvolvimento Urbano Integrado (FNDUI), as fontes de financiamento destes serviços não receberam um tratamento adequado, restando inalterado o quadro de forte heterogeneidade existente entre os municípios, o que pode comprometer a participação dos municípios maiores e com maior capacidade de arrecadação orçamentária, resistentes a transferir recursos para beneficiar municípios vizinhos.

\section{Urbanização periférica: autoconstrução e cidadania insurgente}

Após experimentar tais avanços institucionais na política urbana, havia expectativas de que os brasileiros estivessem vivendo em cidades mais bem ordenadas e com melhor oferta de infraestrutura urbanística e social. Temos, afinal, vários novos planos nacionais, além de instrumentos jurídicos e urbanísticos para controlar a dinâmica das nossas cidades. Não é esse, contudo, o cenário atual, pois segue em vigor o processo de urbanização periférico que nos tem caracterizado desde o século passado.

A urbanização periférica é caracterizada pela negligência em relação à política urbana que contribuísse para estimular um processo de urbanização inclusivo. Ao longo das 5 décadas (1930-80) em que a industrialização levou o país a crescer a taxas anuais médias de 7\% do PIB, houve intenso processo de urbanização e formação de áreas metropolitanas. Neste contexto, as migrações rural-urbanas pressionaram a demanda por terra urbana sem que o poder público conseguisse, ou mesmo tentasse, controlar a especulação fundiária. Ao contrário, a política habitacional do BNH contribuiu para a expansão extensiva das cidades ao localizar nas franjas urbanas os empreendimentos imobiliários para a população de baixa renda. Houve, é verdade, importante oferta de crédito para esses empreendimentos, mas a sua localização periférica sem o cumprimento da legislação que requeria investimento em infraestrutura urbana produziu moradias isoladas das redes de infraestrutura.

Para além da contribuição do BNH, houve enorme produção imobiliária baseada na autoconstrução nas periferias urbanas, inclusive apoiada por financiamento do mesmo BNH para compra de material de construção (Programa João de Barro). Essa urbanização extensiva autoconstruída foi percebida como solução para o problema da falta de habitação na década de 1980 , em que a moradia era vista sobretudo como construção de casas. Ao longo dos anos 1990, a teoria urbana evoluiu para buscar a moradia adequada, aquela situada em área dotada de infraestrutura urbana. Assim, o lugar dos pobres na metrópole passou a depender primeiro da autoconstrução, ficando a regularização urbanística para depois.

Nas décadas seguintes, ao período de intensa industrialização, a indústria foi perdendo participação na estrutura produtiva, mas as maiores cidades seguiram concentrando espacialmente a população e as atividades econômicas, tornando-se economias de serviços. Esse é um movimento que ainda tem prevalecido sobre a desconcentração regional associada à elevação do peso do agronegócio e do extrativismo mineral. 
Depois de quase duas décadas em vigor, o Estatuto da Cidade tem sido avaliado como um avanço normativo que frustrou as expectativas por maior ordenamento urbano (Maricato, 2011). Especialmente as grandes cidades passaram a enfrentar novos desafios, como, por exemplo, insegurança pública e mobilidade urbana inadequada. Esta última foi agravada pela ampla expansão das cidades, com a produção de moradia popular em locais cada vez mais distantes das periferias dos principais polos de emprego, gerando mais movimento pendulares por parte da população. A maior distância dessas moradias é explicada pela elevação do preço da terra nos locais que contam com mais serviços públicos. Já o isolamento dessa urbanização periférica torna seus residentes ainda mais vulneráveis a questões de segurança pública.

Mesmo diante de tal evidência, quando o governo federal instituiu um novo programa habitacional dirigido à população com baixos rendimentos, o Programa Minha Casa Minha Vida, repetiu a experiência do BNH de localizar nas áreas periféricas das cidades seus empreendimentos imobiliários (Santos; Vasques, 2019; Compans, 2012). E a explicação para isso segue sendo o preço da terra urbana, maior nas as áreas que contam com infraestrutura urbana e que são polos de oportunidades de trabalho.

Ainda assim, tais empreendimentos são defendidos por contribuírem para diminuir o déficit habitacional e promover a regularização fundiária. Mas há estudos que defendem que no caso do município do Rio de Janeiro, sede dos jogos olímpicos de verão de 2016, os empreendimentos serviram para realojar pessoas que foram removidas das áreas que receberam investimentos contratados por causa do evento esportivo (Santos; Vasques, 2019; Medeiros, 2013).

Apesar das muitas críticas em relação a sua efetividade, os avanços normativos em prol de um urbanismo social, suscitaram novos movimentos sociais, chamados por Holston (2013) de cidadania insurgente. Segundo o mencionado autor, a urbanização periférica, em contexto de aumento dos direitos sociais recepcionados pela Constituição de 1988, permitiu que os pobres pudessem se defender com a linguagem dos direitos. $\mathrm{E}$, assim, se organizassem para pressionar o Estado a estender até a periferia a infraestrutura urbanística. Essa tem sido a estratégia da urbanização periférica: produzir moradias sem obedecer a legislação que tornou obrigatória a implantação de serviços urbanos; depois constituir uma força política para defender que o poder público implante esses serviços. Ao lograr sucesso nessa luta, os pobres sentem-se responsáveis pela conquista e passam a ter um sentimento de pertencimento mais forte àquele território. E mais, ainda que não consigam regularizar a posse e/ou propriedade de suas moradias, a linguagem dos direitos tem impedido remoções, em linha com o direito social à moradia (Holston, 2013).

Essa extensão da cidade até à periferia, no entanto, gera um custo adicional para os governos municipais. Esses já estão comprometidos com o cofinanciamento das despesas com políticas de acesso aos direitos sociais (especialmente Educação e Saúde), políticas descentralizadas e de execução destes governos, embora formuladas pela União. Tais gastos competem com o desenvolvimento urbano por alocação 
orçamentária, o que tem resultado em perda de sua participação percentual no orçamento municipal (Santos, 2017).

A diminuição do orçamento municipal com o desenvolvimento urbano poderia ser mitigada por políticas que envolvessem maior cooperação interfederativa, pelo menos no que tange aos serviços públicos de interesse comum. Esse era o objetivo do Estatuto da Metrópole. No entanto, constatou-se que após a entrada em vigor desde 2015, o período obrigatório de 3 anos para que os municípios que fossem parte de aglomerados urbanos elaborassem seus planos diretores urbanos integrados foi revogado pela Lei 13.683/2018 (Santos et al, 2019). Do mesmo modo, ficou adiada sem prazo definido a criação de uma autoridade metropolitana, ainda que já tenham sido criadas e/ou indicados órgãos já existentes para cumprir as funções correspondentes em vários estados da federação. Mas a resistência de cidades maiores em participar desses governos metropolitanos segue em curso, como é o caso do Município do Rio de Janeiro, que questionou judicialmente a criação do Instituto Rio Metrópole alegando afronta ao pacto federativo que garante autonomia dos municípios frente aos governos estaduais.

A guisa de conclusão, é possível sugerir que a regulação urbanística desse processo de urbanização periférica tem sido impedida pelo aumento sistemático do preço da terra urbana e que as políticas públicas de habitação social têm produzido moradias que afirmam, e não controlam, a urbanização periférica por conta do mais baixo preço da terra nas localidades em que essas políticas são executadas. Assim sendo, pudemos verificar concretamente, em estudo sobre regularização fundiária, expansão urbana e licenciamentos imobiliários no município do Rio de Janeiro, que a atividade estatal voltada a impedir a reprodução das condições de irregularidade fundiária e urbanística tende a tornar-se um processo de "enxugar gelo", por deixar de voltar-se ao estoque de produção imobiliária irregular para agir como um fluxo crescente dessa produção também (Santos e Cruz, 2018). Como agravante, constata-se a ausência de articulação entre as políticas urbanas para levar "a cidade" até suas áreas periféricas, o que tem geralmente ocorrido como resultado da chamada cidadania insurgente.

\section{REFERÊNCIAS}

BECKER, B. e EGLER, C. Brasil. Uma potência regional na Economia-Mundo. Rio de Janeiro: Bertrand Brasil, 1993.

BOTELHO, A. O urbano em fragmentos: a produção do espaço e da moradia pelas práticas do setor imobiliário. São Paulo: Annablume/FAPESP, 2007.

CASTELLS, M. A sociedade em rede. São Paulo: Paz e Terra, 1999.

CINTRA A. O. "Planejando as cidades: política ou não política?". In: CINTRA, A. O. e HADDAD, P. R. (org.). Dilemas do Planejamento Urbano no Brasil. São Paulo: Zahar, 1978.

COPANS, R. "Minha Casa Minha Vida: o revival do BNH?". In SANTOS, A. et al (org.). Rio de Janeiro: um território em mutação. Rio de Janeiro: Gramma/FAPERJ, 2012. 
COSTA, S. S. Loteamentos irregulares e clandestinos: a cidade e a lei. Rio de Janeiro: Lumen Juris , 2001.

GLAESER, E. Os centros urbanos: a maior invenção da humanidade. Rio de Janeiro: Elsevier, 2011.

HALL, P. “megaciudades, ciudades mundiales y ciudades globales”. In: MARTIN, A. (org.). Lo Urbano. Barcelona: Ediciones UPC, 2004. HARVEY, D. O enigma do capital. São Paulo: Boitempo, 2011.

HOLSTON, J. Cidadania Insurgente: disjunções da democracia e da modernidade no Brasiil. São Paulo: Companhia das Letras, 2013. JACOBS, Jane. Morte e Vida nas Grandes Cidades. São Paulo: Martins Fontes, 2003.

MARICATO, E. O impasse da política urbana no Brasil. Petrópolis: Vozes, 2011.

MONTE-MÓR, Roberto Luís. A questão urbana e o planejamento urbano-regional no Brasil contemporâneo. In: C. C. Diniz \& M. B. Lemos (Eds.). Economia e Território. Belo Horizonte: UFMG, 2005, pp. 429-446.

SANTOS, Angela M. S. P. Política Urbana no Contexto Federativo Brasileiro. Aspectos institucionais e financeiros. Rio de Janeiro: EDUERJ, 2017.

SANTOS, Angela M. S. P.. “Políticas sociais em xeque: Impacto da crise sobre as finanças municipais”. In: Boletim Petróleo, Royalties e Região. Ano XVI, n. 61 - dezembro de 2018.

SANTOS, Angela Moulin Simões Penalva; CRUZ, Carlos Eduardo de Souza. Regularização Fundiária: de seu avanço institucional à reprodução crescente do problema que a originou. In: CORREIA, Arícia Fernandes (org.), Direito da Regularização Fundiária Urbana Sustentável: pesquisa, teoria e prática sobre a Lei Federal n. 13.465/2017. Juiz de Fora: Editar, 2018, pp. 35-53.

SANTOS, Angela M. S.P. e VASQUES, Pedro. "The Brazilian housing program “Minha Casa Minha Vida” in Rio de Janeiro: an analysis of its social and urban aspects". In: Seminário CITTA 2019, Porto/PT, 20 de setembro de 2019.

SANTOS et al. "Governança Territorial: o que avançou com o Estatuto da Metrópole?". Revista Direito da Cidade, v.12, n.2, 2019.

SANTOS, M. A urbanização brasileira. São Paulo: HUCITEC, 1996.

SASSEN, S. Los espectros de la globalización. Buenos Aires: Fondo de Cultura Economica, 2003.

STOPRPER, M.A e VENABLES, A. “O burburinho: a força econômica da cidade”. In: DINIZ, C. e LEMOS, M. (org.). Economia e Território. Belo Horizonte: UFMG, 2005.

\section{Fontes consultadas}

IBGE: Contas Regionais, 2017

IBGE: Censos demográficos, 2000 e 2010

IBGE: MUNIC, 2001

Fundação João Pinheiro. Déficit habitacional, 2013.

Ministério do Trabalho, CAGED, 2000 e 2010. 